\title{
Detection of Strongyloides stercoralis infection among cancer patients in a major hospital in Kelantan, Malaysia
}

\author{
AbdelRahman Mohammad Zueter ${ }^{1}$, MSc, Zeehaida Mohamed ${ }^{1}$, MD, MPath, Abu Dzarr Abdullah'², MD, MMed, \\ Norsarwany Mohamad ${ }^{3}$, MD, MMed, Norsyahida Arifin $^{3}$, PhD, Nurulhasanah Othman ${ }^{3}$, PhD, Rahmah Noordin 4 , PhD
}

INTRODUCTION Strongyloidiasis is one of the most commonly neglected but clinically important parasitic infections worldwide, especially among immunocompromised patients. Evidence of infection among immunocompromised patients in Malaysia is, however, lacking. In this study, microscopy, real-time polymerase chain reaction (PCR) and enzyme-linked immunosorbent assays (ELISAs) were used to detect Strongyloides stercoralis (S. stercoralis) infection among cancer patients in a Malaysian hospital.

METHODS A total of 192 stool and serum samples were collected from cancer patients who were receiving chemotherapy with or without steroid treatment at a hospital in northeastern Malaysia. Stool samples were examined for S. stercoralis using parasitological methods and real-time PCR. Serology by ELISA was performed to detect parasite-specific immunoglobulin $\mathrm{G}$ (IgG), IgG4 and immunoglobulin E (IgE) antibodies. For comparison, IgG4- and IgG-ELISAs were also performed on the sera of 150 healthy individuals from the same area.

RESULTS Of the 192 samples examined, 1 (0.5\%) sample was positive for S. stercoralis by microscopy, 3 (1.6\%) by real-time PCR, 8 (4.2\%) by IgG-ELISA, 6 (3.1\%) by IgG4-ELISA, and none was positive by IgE-ELISA. In comparison, healthy blood donors had significantly lower prevalence of parasite-specific IgG $(2.67 \%, p<0.05)$ and IgG4 $(2.67 \%, p<0.05)$ responses. CONCLUSION This study showed that laboratory testing may be considered as a diagnostic investigation for S. stercoralis among immunocompromised cancer patients.

Keywords: cancer patients, ELISAs, microscopy, real-time PCR, Strongyloides stercoralis

\section{INTRODUCTION}

Strongyloides stercoralis (S. stercoralis) is endemic in many tropical and subtropical countries, with an estimated prevalence of up to $11 \%$ in some areas of Southeast Asia. ${ }^{(1)}$ A study on the prevalence of $S$. stercoralis infection in Thailand found that $11 \%$ of the study population had $S$. stercoralis larvae in their stool samples, while $45 \%$ were seropositive. ${ }^{(2)}$ In Brazil, parasitological and serological investigations revealed the prevalence of strongyloidiasis among cancer patients to be $13 \% .^{(3)}$

Strongyloides larvae gain access to the body through transcutaneous and faecal-oral routes, initiating acute infection following an incubation period.(4) Strongyloidiasis has variable manifestations, ranging from asymptomatic chronic infection to acute hyperinfection and fatal disseminated syndrome. ${ }^{(5)}$ However, adult worms can chronically survive in hosts for decades while causing merely intermittent gastrointestinal symptoms. The most severe effects of Strongyloides infections are seen in patients with cancer and autoimmune diseases who receive immunosuppressive therapy. Such therapy dysregulates the immune system, causing the dormant $S$. stercoralis infection to be reactivated in these patients, leading to diseases that may prove fatal. ${ }^{(6)}$ Therefore, reliable screening of cancer patients who are at risk for strongyloidiasis relapse could be necessary for accurate diagnosis and appropriate treatment before and during immunosuppressive therapy. ${ }^{(7)}$
Routine diagnosis of strongyloidiasis is usually performed by microscopic examination of stool samples, although this method is reported to have low sensitivity ${ }^{(8)}$ and leads to frequent misdiagnosis of the disease. ${ }^{(7)}$ Several immunodiagnostic assays have been established and evaluated, and these have shown variable sensitivities and specificities based on the antigen preparation, immunoglobulin isotypes and population tested. Detection of $S$. stercoralis DNA in stool samples using real-time polymerase chain reaction (PCR) has also been shown to be a sensitive and specific method for diagnosis of the infection. ${ }^{(9)}$

To our knowledge, no study has reported on the prevalence of Strongyloides infection among immunocompromised patients in Malaysia. The availability of locally relevant data is important in order to determine whether screening for Strongyloides should be considered during the management of these patients. As a step toward addressing this issue, the present study aimed to provide evidence of Strongyloides infection, using microscopy, real-time PCR and immunoassays, among cancer patients treated at one of the major hospitals in Malaysia.

\section{METHODS}

This was a prospective cross-sectional study performed using samples from cancer patients who were treated at a major hospital in Kelantan, Malaysia. The sample size was calculated based on the prevalence of strongyloidiasis reported in previous related studies. ${ }^{(2,10)}$ This study was approved by the Human

\footnotetext{
${ }^{1}$ Department of Medical Microbiology and Parasitology, ${ }^{2}$ Department of Medicine, ${ }^{3}$ Department of Paediatrics, School of Medical Sciences, Universiti Sains Malaysia, Kelantan, ${ }^{4}$ Institute for Research in Molecular Medicine, Universiti Sains Malaysia, Penang, Malaysia

Correspondence: Dr Rahmah Noordin, Professor, Institute for Research in Molecular Medicine (INFORMM), Universiti Sains Malaysia, 11800 Penang, Malaysia. rahmah8485@gmail.com
} 
Research Ethics Committee at Universiti Sains Malaysia, Malaysia.

A total of 192 stool and serum samples were collected from cancer patients undergoing chemotherapy with or without steroid treatment between December 2010 and August 2011. Chemotherapeutic agents were administered to the patients in regimens for the treatment of various types of cancers, using standard chemotherapy for underlying diseases. Patients who were found to be positive for Strongyloides infection by microscopy and/or real-time PCR were prescribed the appropriate anthelmintic treatment. In addition, 150 previously collected healthy serum samples from blood donors at the same hospital were used to determine the prevalence of parasite-specific immunoglobulin G (IgG) and IgG4 antibodies in the control group.

For the purpose of this study, neutropenia was defined as absolute neutrophil count $(\mathrm{ANC}) \leq 1.5 \times 10^{3} \mathrm{cells} / \mu \mathrm{L}$, while eosinophilia was defined as absolute eosinophil count $(\mathrm{AEC}) \geq 0.400 \times 10^{3}$ cells/ $\mu \mathrm{L} .{ }^{(11)}$ Direct smear and formalin-ether concentration examinations were conducted on the stool samples. Triple smears were made for each technique, followed by systematic microscopic examination. Primers and detection probes specific for the $S$. stercoralis $18 \mathrm{~S}$ rRNA sequence were used in our study, as previously described. ${ }^{(8,10)}$ The PCR reaction, thermal profile, concentrations of primers and probes, and interpretation of results were based on the study by Basuni et al. ${ }^{(8)}$ For internal control, the phocine herpesvirus 1 (PhHV-1)-specific primers and probe set consisted of the forward primer PhHV-267s, reverse primer PhHV-337as and the double-labelled probe PhHV-305tq. The primers and probes used in our study showed high sensitivity and $100 \%$ specificity when tested against DNA controls derived from a wide range of intestinal microorganisms. ${ }^{(10)}$

For DNA amplification, $5 \mu \mathrm{L}$ of DNA extracted from stool specimens was used as a template in a final volume of $25 \mu \mathrm{L}$ with PCR buffer (HotStarTaq Master Mix Kit; QIAGEN, Hilden, Germany), $25 \mathrm{mM}$ magnesium chloride (MBI Fermentas Inc, Amherst, MA, USA), $5 \mathrm{mg} / \mathrm{mL}$ bovine serum albumin (Sigma Aldrich Co, St Louis, MO, USA), $25 \mathrm{mM}$ each of $S$. stercoralisand PhHV-1-specific primers (First BASE Laboratories Sdn Bhd, Selangor, Malaysia), and $10 \mathrm{mM}$ each of S. stercoralis- and PhHV-1-specific double-labelled probes (Eurogentec SA, Seraing, Belgium). Amplification consisted of 15 mins at $95^{\circ} \mathrm{C}$, followed by 50 cycles of $15 \mathrm{~s}$ at $95^{\circ} \mathrm{C}$ and $1 \mathrm{~min}$ at $60^{\circ} \mathrm{C}$. Amplification, detection and data analysis were performed using the Rotor-Gene 6000 real-time PCR machine (Rotorgene-Q, Hilden, Germany). Included in each real-time PCR run were PCR mixtures without DNA template as the negative control and DNA of $S$. stercoralis as the positive control. The PhHV-1 viral DNA internal control ensured that there was no inhibition during DNA extraction and PCR reaction. During PCR, the PhHV-1 DNA should be detected in all samples within an acceptable $\mathrm{Ct}$ (threshold cycle) range $(33<\mathrm{Ct}<37)$. If the $\mathrm{Ct}$ value of $\mathrm{PhHV}-1$ was $>37$, DNA extraction was repeated. Amplification reactions for detecting S. stercoralis were repeated to confirm the results of samples with $\mathrm{Ct}$ values $>35$ (since this value indicated the presence of few DNA copies), and the assay was considered negative when $\mathrm{Ct} \geq 40$ or no amplification curve was obtained. Preparation of the master mix, extraction of DNA and handling of PCR products were all performed in separate rooms using dedicated pipettes and equipment to prevent contamination.

Previously optimised IgG-enzyme-linked immunosorbent assays (ELISAs) using S. stercoralis L3 lysate antigen were found to give results comparable to a commercial IgG-ELISA kit (Strongyloides Serology Microwell ELISA; IVD Research Inc, Carlsbad, CA, USA). To detect parasite-specific IgG4 and immunoglobulin E (IgE) antibodies, ELISA parameters were also optimised. ${ }^{(12)}$ Flat-bottom polystyrene high-bind ELISA microwell plates (Nunc MaxiSorp; Nalge Nunc International, Rochester, NY, USA) were coated overnight at $4^{\circ} \mathrm{C}$ with $5 \mu \mathrm{g} / \mathrm{mL}$ of $S$. stercoralis L3 lysate antigen in $0.06 \mathrm{M}$ carbonate buffer $(\mathrm{pH}$ 9.6) for IgG-ELISA, or with $10 \mu \mathrm{g} / \mathrm{mL}$ of the same antigen for IgG4- and IgE-ELISAs. All washings and incubations were performed on a microplate shaker placed in an incubator at $37^{\circ} \mathrm{C}$. Subsequently, the coated wells were washed five times (5 mins each) using phosphate buffered saline with $0.05 \%$ Tween $^{\circledR} 20$. The wells were then blocked with 3\% bovine serum albumin (Sigma Aldrich Co, St Louis, MO, USA) for one hour. After a washing step, $100 \mu \mathrm{L} /$ well of diluted serum samples were added and incubated for $2 \mathrm{hrs}$. The dilutions of sera were 1:200 for IgG and 1:100 for IgE and IgG4 assays. After another washing step, $100 \mu \mathrm{L} /$ well of antihuman IgG/IgG4/IgE conjugated to horseradish peroxidase (Invitrogen, Carlsbad, CA, USA) was diluted in phosphate buffered saline $(\mathrm{pH} 7.2)$ and incubated for 30 mins. The dilutions of sera were $1: 8,000,1: 4,500$ and $1: 2,000$ for $\lg G$, $\lg G 4$ and $\lg E$, respectively. The wells were then washed and $100 \mu \mathrm{L} /$ well of ABTS ELISA peroxidase substrate (2,2'-azino-bis[3-ethylbenzothiazoline-6sulphonic acid]-diammonium salt; Roche Diagnostics, Mannheim, Germany) was added and incubated for 30 mins in the dark.

Optical density (OD) was read at $405 \mathrm{~nm}$, with $490 \mathrm{~nm}$ as the reference wavelength, using an ELISA reader (Multiskan ${ }^{\circledR}$ Spectrum; Thermo Scientific, Rockford, IL, USA). The result was considered to be positive when the OD value exceeded the cut-off values (0.21 for IgG4-ELISA; 0.2 for IgE-ELISA; 0.34 for IgG-ELISA). Cut-off values were previously determined using 30 serum samples from healthy individuals whose stool samples were negative for soil-transmitted helminths by microscopy and real-time PCR.

Treatment was given to three patients who tested positive for Strongyloides - one patient via stool microscopy and two via real-time PCR. The patients were treated with oral albendazole (400 mg/day) for three days and intravenous tazocin ( 4.5 g every 6 hrs) for five days. However, the patient who tested positive for Strongyloides via stool microscopy died due to multiorgan failure. After five weeks, all tests were repeated for the other two patients.

\section{RESULTS}

The median and mean ages of the patients in our study were 44.0 and 39.1 (range 3-80) years, respectively. The study 
sample included patients with various types of malignancies, including haematological malignancies ( $\mathrm{n}=68,35.4 \%$ ) and solid organ tumours ( $\mathrm{n}=124,64.6 \%$ ). A majority of patients had received chemotherapy and steroids. About half of the patients ( $\mathrm{n}=92,47.9 \%$ ) had completed the second and third cycles of chemotherapy at the time of sampling. A total of 69 (35.9\%) patients were immunosuppressed (ANC $\leq 1.5 \times 10^{3}$ cells $/ \mu \mathrm{L}$ ), and these included patients who tested positive for Strongyloides $(\mathrm{n}=11)$ via PCR and/or microscopy. The remaining 123 (64.1\%) patients had normal immunological status. Out of 100 symptomatic patients, $82(82.0 \%)$ had gastrointestinal symptoms. AEC was elevated $\left(\geq 0.400 \times 10^{3}\right.$ cells $\left./ \mu \mathrm{L}\right)$ in $26(13.5 \%)$ of the 192 patients. Among the patients who were positive for Strongyloides, eosinophilia was seen in $3(27.3 \%)$ of the 11 patients who tested positive via PCR and/or microscopy. Table I compares the data of patients found to be positive for Strongyloides by at least one of the tests and those who were negative by all tests. Among those found to be positive by at least one of the tests, there were higher proportions of patients with ANC $\leq 1.5 \times 10^{3} \mathrm{cell} / \mu \mathrm{L}$ and patients with eosinophilia $\left(\geq 0.400 \times 10^{3}\right.$ eosinophils $\left./ \mu \mathrm{L}\right)$, when compared to patients who were found to be negative by all tests.

Out of the 192 patients in the study, stool microscopy for Strongyloides rhabditiform larvae was positive for only 1 (0.5\%) patient. This patient was neutropenic and eosinophilic, and had 1-3 rhabditiform larvae per high-power field in fresh stool samples on two occasions within ten days before and after treatment. In all, $3(1.6 \%)$ patients tested positive for Strongyloides infection via real-time PCR; the sample that was positive for Strongyloides rhabditiform larvae by microscopy was also positive by PCR. Serological diagnosis showed that $8(4.2 \%)$ samples tested positive for Strongyloides by IgG-ELISA, 6 (3.1\%) by IgG4-ELISA, and none was positive by IgE-ELISA (Table II). Table III compares the findings of the parasitological, molecular and immunological investigations performed among patients who were positive by any of the above tests.

Repeat serum samples from the two patients who received treatment showed positive anti-Strongyloides IgG antibody even though other serological tests were negative (data not shown). The anti-Strongyloides $\operatorname{lgG}$ antibodies titre declined in one patient (OD from 2.800 to 1.403), but was slightly increased in the second patient (OD from 0.113 to 0.242 ). Repeat stool microscopy and real-time PCRs were negative for both patients.

The prevalence of both parasite-specific IgG and IgG4 antibodies among healthy blood donors was $2.67 \%$ in our study. Unpaired $t$-test (with Welch correction) revealed that the incidences of parasite-specific $\operatorname{lgG}$ and $\lg \mathrm{G} 4$ antibodies in controls were significantly lower than those in cancer patients (IgG-ELISA, $\mathrm{p}=0.0244 ; \operatorname{lgG} 4-\mathrm{ELISA}, \mathrm{p}=0.0463$ ).

\section{DISCUSSION}

There is currently no consensus on the screening approaches for S. stercoralis in suspected patients. Routine diagnosis of strongyloidiasis involves a combination of stool microscopy
Table I. Patient characteristics with respect to the presence of Strongyloides in the stool samples.

\begin{tabular}{|c|c|c|}
\hline \multirow[t]{2}{*}{ Characteristic } & \multicolumn{2}{|c|}{ No. of patients } \\
\hline & $\begin{array}{l}\text { Positive } \\
(n=11)\end{array}$ & $\begin{array}{l}\text { Negative } \\
(n=181)\end{array}$ \\
\hline \multicolumn{3}{|l|}{ Gender } \\
\hline Male & 8 & 78 \\
\hline Female & 3 & 103 \\
\hline Mean age (yrs) & 32.72 & 36.64 \\
\hline \multicolumn{3}{|l|}{ Diagnosis } \\
\hline Solid organ tumour & 9 & 115 \\
\hline Lymphoma & 1 & 20 \\
\hline Leukaemia & 1 & 46 \\
\hline \multicolumn{3}{|l|}{ Symptom } \\
\hline GI and/or respiratory symptoms & 8 & 92 \\
\hline No symptom & 3 & 89 \\
\hline \multicolumn{3}{|l|}{ ANC } \\
\hline Mean ANC ( $\times 10^{3}$ cells $\left./ \mu \mathrm{L}\right)$ & 1.73 & 4.5 \\
\hline ANC $\leq 1.5 \times 10^{3}$ cells $/ \mu \mathrm{L}$ & 8 & 61 \\
\hline \multicolumn{3}{|l|}{ AEC } \\
\hline Mean AEC (× $10^{3}$ cells $\left./ \mu \mathrm{L}\right)$ & 0.38 & 0.24 \\
\hline $\mathrm{AEC} \geq 0.40 \times 10^{3}$ cells $/ \mu \mathrm{L}$ & 3 & 23 \\
\hline \multicolumn{3}{|l|}{ Cancer treatment } \\
\hline Chemotherapy only & 1 & 15 \\
\hline Chemotherapy + steroids & 9 & 163 \\
\hline Chemotherapy + radiotherapy & 1 & 3 \\
\hline Total body irradiation & - & - \\
\hline
\end{tabular}

AEC: absolute eosinophil count; ANC: absolute neutrophil count; Gl: gastrointestinal

Table II. Detection of Strongyloides stercoralis infection among cancer patients $(n=192)$ using direct and indirect diagnostic methods.

\begin{tabular}{llll}
\hline Method & \multicolumn{3}{c}{ No. (\%) } \\
\cline { 2 - 4 } & Positive & Negative & $\begin{array}{c}\text { Detection rate } \\
\text { among positive } \\
\text { patients* }(\mathbf{n}=11)\end{array}$ \\
\hline Direct method & & & $1(9.0)$ \\
Microscopy & $1(0.5)$ & $191(99.5)$ & $3(27.2)$ \\
Real-time PCR & $3(1.6)$ & $189(98.4)$ & $8(72.7)$ \\
Indirect method & & & $6(54.5)$ \\
IgG-ELISA & $8(4.2)$ & $184(95.8)$ & $0(0)$ \\
IgG4-ELISA & $6(3.1)$ & $186(96.9)$ & $192(100)$ \\
IgE-ELISA & $0(0)$ & $190)$ & \\
\hline
\end{tabular}

*Patients who were positive using any of the diagnostic methods. ELISA: enzyme-linked immunosorbent assay; IgE: immunoglobulin E; IgG: immunoglobulin G; PCR: polymerase chain reaction

and/or culture techniques. Detection of the helminth larvae in faecal samples can, however, be difficult, and the method is insufficiently sensitive due to the intermittent larval output in stools, thus limiting its use as a standalone diagnostic technique for Strongyloides infection. ${ }^{13,14)}$

The detection of parasitic DNA in faecal samples using real-time PCR has been shown to be a more sensitive and specific method for the diagnosis of strongyloidiasis than faecal examination. . $810,15,16)$ Even so, since PCR positivity depends on the presence of $S$. stercoralis larvae or their DNA in the samples, the very low larval output seen in the stools of patients with chronic infection may reduce the utility of molecular diagnosis in these patients. ${ }^{(6,7)}$ 
Table III. Results of parasitological, molecular and immunological investigations among patients who were positive by any of the tests.

\begin{tabular}{lccccc}
\hline Patient & \multicolumn{5}{c}{ Investigation } \\
\cline { 2 - 6 } & $\begin{array}{c}\text { Stool } \\
\text { microscopy }\end{array}$ & $\begin{array}{c}\text { Real-time } \\
\text { PCR }\end{array}$ & $\begin{array}{c}\text { IgG } \\
\text { ELISA }\end{array}$ & $\begin{array}{c}\text { IgG4 } \\
\text { ELISA }\end{array}$ & $\begin{array}{c}\text { IgE } \\
\text { ELISA }\end{array}$ \\
\hline 4 & + & + & + & + & - \\
5 & - & - & - & + & - \\
25 & - & - & + & - & - \\
50 & - & - & - & + & - \\
59 & - & - & + & + & - \\
62 & - & - & - & + & - \\
65 & - & - & + & - & - \\
66 & - & + & + & - & - \\
111 & - & - & + & - & - \\
147 & - & - & + & - & - \\
192 & - & - & + & + & - \\
\hline
\end{tabular}

+: positive; -: negative; ELISA: enzyme-linked immunosorbent assay; IgE: immunoglobulin E; IgG: immunoglobulin G; PCR: polymerase chain reaction

In our study, evidence of the presence of parasite was obtained by means of DNA detection in 3 out of $192(1.6 \%)$ samples, with one of these patients being positive on microscopy as well. The three PCR-positive patients were among those with gastrointestinal symptoms. It might have been possible to obtain higher rates of definitive microscopic detection if more sensitive parasitological methods such as the Baermann technique and faecal culture were used. In a recent study by our group, the prevalence of $S$. stercoralis among non-cancer patients with gastrointestinal disorders at the same hospital using the same real-time PCR protocol was found to be $1.33 \%(3 / 225) .{ }^{(17)}$ This was similar to the rate of detection of $S$. stercoralis DNA in the present study, thus indicating that both groups of patients have a similar risk of acquiring $S$. stercoralis infection. However, due to immunosuppressive therapy consisting of chemotherapeutic drugs and/or corticosteroids, as well as the progressive nature of many tumours, cancer patients who are generally immunosuppressed are at risk of developing hyperinfection. ${ }^{(14)}$ Numerous reports have documented the association of immunosuppressive therapy and steroids as a primary cause of fatal Strongyloides hyperinfection in cancer patients. ${ }^{(18-20)}$

Serodiagnosis has been reported to provide useful indirect evidence for laboratory diagnosis of Strongyloides infection in both immunosuppressed and immunocompetent patients. ${ }^{(3)}$ The most convenient and widely used procedure is indirect ELISA, which detects specific serum IgG, the $\lg$ subclasses (IgG1, IgG2 and IgG4) and IgE antibodies using crude extracts of $S$. stercoralis larvae. ${ }^{(7)}$ The serological pattern among the patients in the present study was consistent with that in previous reports, i.e. in the chronic phase of Strongyloides infection, there is a decline in the level of $\lg \mathrm{E}$, while the level of total $\lg$ G remains elevated and IgG4 becomes detectable. ${ }^{(21,22)}$

Furthermore, we found that the ELISAs for the detection of Strongyloides-specific IgG and IgG4 antibodies among cancer patients were significantly higher than those among healthy blood donors at the same hospital (data not shown). In another study by our group involving samples from 26 immunocompetent patients with parasitologically proven infection and 55 control samples, Strongyloides IgG-ELISA was found to be significantly more sensitive but less specific than IgG4-ELISA $(p<0.05)$. $^{(12)}$ This suggests that the findings of two patients who were $\operatorname{lgG} 4$ negative but positive by IgG-ELISA and real-time PCR in our study could be attributed to the lower sensitivity of the IgG4 assay. Similarly, findings of patients who are negative by PCR and IgG4-ELISA but positive by IgG-ELISA may be explained by the lower specificity of the IgG assay. The general immune dysfunction in immunosuppressed cancer patients may also play a role in some of the above seemingly discrepant results.

All PCR or microscopy positive patients in the present study were clearly immunosuppressed at the time of sampling (ANC $\leq 1.5 \times 10^{3}$ cells $/ \mu \mathrm{L}$ ). This result is consistent with two other published studies, which reported the activation of infection in patients with low immunity caused by chemotherapy. ${ }^{(19,21)}$ Our observation that there is a higher percentage of patients with low ANC $\left(\leq 1.5 \times 10^{3}\right.$ cells $\left./ \mu \mathrm{L}\right)$ among those who were positive for Strongyloides infection, as compared to those who were found negative by all tests, was also in agreement with earlier results.

Eosinophil levels have been reported to be elevated during early Strongyloides infection, decreased during the chronic phase and mildly elevated for many years ${ }^{(23)}$ while being absent during immune suppression. ${ }^{(6)}$ In the present study, AEC was elevated in all patients who tested positive by PCR or microscopy. Eosinophilia was also reported in another 23 patients in our study. However, this finding might have been incidental or nonspecific since eosinophilia could have also developed as a result of the side effects of chemotherapy, allergy or other parasitic infection or clinical conditions. Moreover, since elevation in eosinophil counts is commonly mild and nonspecific, AEC measurements are not helpful in the differential diagnosis of patients with suspected strongyloidiasis. ${ }^{(13,24)}$

In concordance with other studies, a combination of diagnostic procedures yields higher detection rates when compared to parasitological techniques alone. ${ }^{(8,10)}$ Follow-up of our two patients who underwent anthelmintic treatment showed that it was effective in eliminating adult Strongyloides worms and Strongyloides larvae from the patients' intestines, as evidenced by the negative repeat real-time PCR results (data not shown). As expected, anti-Strongyloides IgG antibody titre declined in one patient. However, the titre was increased in the second patient. A possible explanation for this may be that, in this patient, a much higher number of larvae and/or adult worms had caused the release of more antigens upon death, which may have in turn triggered increased antibody production. These two patients were not treated for strongyloidiasis, in accordance with hospital practice, as there is no clinical indication for the treatment of patients who are seropositive but negative for the parasite or its DNA.

Current recommendations suggest empiric treatment with anthelmintic drugs such as albendazole prior to chemotherapy in patients who are at risk of Strongyloides infection. ${ }^{(25)}$ Although the number of positive patients in our study was small, it was worthwhile to administer albendazole to patients receiving 
chemotherapy at our hospital, since the drug is very safe, easy to administer orally and beneficial to patients by way of preventing or minimising serious complications such as hyperinfection syndrome. Albendazole doses of $400 \mathrm{mg}$ twice daily for three days is usually recommended. (26) Further studies would likely be required to ascertain whether this recommendation should be extended to other hospitals in Kelantan and neighbouring Malaysian states.

Our study was not without limitations. First, there was an absence of baseline data on tests performed before immunosuppression treatment was initiated for cancer patients. Extensive follow-up studies on a larger scale, using both direct and indirect diagnostic methods, are thus warranted, in order to determine the actual prevalence of Strongyloides infection in the local population. Preferably, these studies should involve hospitals from various regions in Malaysia known to be endemic for soiltransmitted helminth infections. Nevertheless, our results could provide useful insights when determining the adequate sample size that would allow robust statistical analysis for future studies.

In conclusion, our study provided evidence of the occurrence of $S$. stercoralis infection among cancer patients at a hospital in Malaysia. Laboratory testing may be considered as one of the investigations for the diagnosis of $S$. stercoralis among this group of immunocompromised patients.

\section{ACKNOWLEDGEMENTS}

This study was funded by the Universiti Sains Malaysia short-term grant (No. 304/PPSP/61312089) and the RU grant (No. 1001/CIPPM/812078). The authors do not have any conflicting interests to declare.

\section{REFERENCES}

1. Genta RM. Global prevalence of strongyloidiasis: critical review with epidemiologic insights into the prevention of disseminated disease. Rev Infect Dis 1989; 11:755-67.

2. Douce RW, Brown AE, Khamboonruang C, Walzer PD, Genta RM. Seroepidemiology of strongyloidiasis in a Thai village. Int J Parasitol 1987; 17:1343-8.

3. Schaffel R, Nucci M, Carvalho E, et al. The value of an immunoenzymatic test (enzyme-linked immunosorbent assay) for the diagnosis of strongyloidiasis in patients immunosuppressed by hematologic malignancies. Am J Trop Med Hyg 2001; 65:346-50.

4. Daubenton JD, Buys HA, Hartley PS. Disseminated strongyloidiasis in a child with lymphoblastic lymphoma. J Pediatr Hematol Oncol 1998; 20:260-3.

5. Ganesh S, Cruz RJ, Jr. Strongyloidiasis: a multifaceted disease. Gastroenterol Hepatol (NY) 2011; 7:194-6.
6. Marcos LA, Terashima A, Canales M, Gotuzzo E. Update on strongyloidiasis in the immunocompromised host. Curr Infect Dis Rep 2011; 13:35-46.

7. Olsen A, van Lieshout L, Marti H, et al. Strongyloidiasis-the most neglected of the neglected tropical diseases? Trans R Soc Trop Med Hyg 2009; 103:967-72.

8. Basuni M, Muhi J, Othman N, et al. A pentaplex real-time polymerase chain reaction assay for detection of four species of soil-transmitted helminths. Am J Trop Med Hyg 2011; 84:338-43.

9. van Doorn HR, Koelewijn R, Hofwegen $\mathrm{H}$, et al. Use of enzyme-linked immunosorbent assay and dipstick assay for detection of Strongyloides stercoralis infection in humans. J Clin Microbiol 2007; 45:438-42.

10. Verweij JJ, Canales M, Polman K, et al. Molecular diagnosis of Strongyloides stercoralis in faecal samples using real-time PCR. Trans R Soc Trop Med Hyg 2009; 103:342-6.

11. Hutchison RE, Schexneider KI. Leukocytic disorders. In: McPherson RA, Pincus MR, eds. Henry's Clinical Diagnosis and Management by Laboratory Methods. Philadelphia: Saunders Elsevier, 2011.

12. Norsyahida A, Riazi M, Sadjjadi SM, et al. Laboratory detection of strongyloidiasis: IgG, IgG4- and IgE ELISAs and cross-reactivity with lymphatic filariasis. Parasite Immunol 2013; 35:174-9.

13. Wirk B, Wingard JR. Strongyloides stercoralis hyperinfection in hematopoietic stem cell transplantation. Transpl Infect Dis 2009; 11:143-8.

14. Keiser PB, Nutman TB. Strongyloides stercoralis in the Immunocompromised Population. Clin Microbiol Rev 2004; 17:208-17.

15. Janwan P, Intapan PM, Thanchomnang T, et al. Rapid detection of Opisthorchis viverrini and Strongyloides stercoralis in human fecal samples using a duplex real-time PCR and melting curve analysis. Parasitol Res 2011; 109:1593-601.

16. Ten Hove R, Van Esbroeck M, Vervoort T, et al. Molecular diagnostics of intestinal parasites in returning travellers. Eur J Clin Microbiol Infect Dis 2009; 28:1045-53.

17. Basuni M, Mohamed Z, Ahmad M, Zakaria NZ, Noordin R. Detection of selected intestinal helminths and protozoa at Hospital Universiti Sains Malaysia using multiplex real-time PCR. Trop Biomed 2012; 29:434-42.

18. Kia EB, Rahimi HR, Mirhendi H, et al. A case of fatal strongyloidiasis in a patient with chronic lymphocytic leukemia and molecular characterization of the isolate. Kor J Parasitol 2008; 46:261-3.

19. Seet RC, Lau LG, Tambyah PA. Strongyloides hyperinfection and hypogammaglobulinemia. Clin Diagn Lab Immunol 2005; 12:680-2.

20. Abdelrahman MZ, Zeehaida M, Rahmah N, et al. Fatal septicemic shock associated with Strongyloides stercoralis infection in a patient with angioimmunoblastic T-cell lymphoma: a case report and literature review. Parasitol Int 2012; 61:508-11

21. Rodrigues RM, de Oliveira MC, Sopelete MC, et al. $\lg \mathrm{M} 1, \lg G 4$, and IgE antibody responses in human strongyloidiasis by ELISA using Strongyloides ratti saline extract as heterologous antigen. Parasitol Res 2007; 101:1209-14.

22. Lindo JF, Lee MG. Strongyloides stercoralis and S. fulleborni. In: Gillespie SH, Pearson RD, eds. Principles and Practice of Clinical Parasitology. 1st ed. New York: John Wiley \& Sons, 2001: 479-92.

23. Brooker S, Bundy DAP. Soil-transmitted helminths (geohelminths). In: Cook GC, Manson P, Zumla A, eds. Manson's Tropical Diseases. 22nd ed. Philadelphia: Saunders Limited, 2009: 1532-8.

24. Siddiqui AA, Berk SL. Diagnosis of Strongyloides stercoralis infection. Clin Infect Dis 2001; 33:1040-7.

25. No authors listed. Parasitic infections. Am J Transplant 2004; 4(Suppl 10):142-55.

26. Roxby AC, Gottlieb GS, Limaye AP. Strongyloidiasis in transplant patients. Clin Infec Dis 2009; 49:1411-23. 